\title{
Exceptional serological and radiological response to sorafenib in 2 patients with advanced hepatocellular carcinoma and chronic hepatitis $C$ viral infection: case report and review of the literature
}

\author{
Catherine Atkin ${ }^{1}$, Philip Earwaker ${ }^{1}$, Arvind Pallan², Shishir Shetty ${ }^{3}$, Pankaj Punia ${ }^{1}$ and Yuk Ting Ma ${ }^{1 *}$
}

\begin{abstract}
Background: In patients with advanced hepatocellular carcinoma (HCC), the multikinase inhibitor sorafenib is the only systemic treatment that has been shown to increase overall survival. However, similar to other tyrosine kinase inhibitors, most patients achieve disease stabilisation radiologically, and only 2-3\% of patients achieve a partial response. Recent exploratory subgroup analyses of the large phase 3 trials have demonstrated that patients with chronic hepatitis $\mathrm{C}$ virus (HCV) infection associated HCC survive longer than those who are negative for HCV. The mechanism underlying this currently remains unknown. A small number of cases of complete response to sorafenib treatment have now been reported worldwide, however a prolonged response has only been reported in 2 cases, both of whom had HCV-related HCC.
\end{abstract}

Case presentation: A 55 year old gentleman was diagnosed with hepatocellular carcinoma and concomitant chronic hepatitis $C$ viral infection. He progressed following transarterial chemoemoblisation treatment and was commenced on sorafenib treatment. His serum alphafetoprotein level normalised within 2 months of treatment and he achieved an almost complete radiological response. This response was maintained for 20 months before the patient progressed. A 75 year old lady was diagnosed with advanced hepatocellular carcinoma and concomitant chronic hepatitis $C$ viral infection. She was commenced on sorafenib treatment but required early dose reductions due to palmar plantar erythrodysesthesia, and liver decompensation. Despite this she achieved an excellent serological and radiological response that was maintained for 24 months.

Conclusions: Our two cases show that patients with HCV-associated HCC can attain excellent responses to sorafenib treatment that is durable. Furthermore, such exceptional responses can be achieved even with dose reductions and treatment breaks.

Keywords: Sorafenib, Hepatocellular carcinoma, Hepatitis C virus infection

\footnotetext{
*Correspondence: y.t.ma@bham.ac.uk

${ }^{1}$ The Cancer Centre, University Hospitals Birmingham NHS Foundation Trust,

Edgbaston, Birmingham B15 2TH, UK

Full list of author information is available at the end of the article
} 


\section{Background}

Hepatocellular carcinoma (HCC) is the 5th most common cancer worldwide, and the 3rd most common cause of cancer death. It often occurs on a background of chronic liver disease, including chronic hepatitis $\mathrm{C}$ $(\mathrm{HCV})$ or hepatitis B (HBV) viral infection, and alcoholic liver disease [1].

Sorafenib, a multikinase inhibitor, is the only systemic treatment shown to increase overall survival in those with advanced HCC $[2,3]$. However only $2-3 \%$ of patients achieve a partial response to sorafenib, with most patients achieving disease stabilisation.

Here we report two cases with advanced hepatocellular carcinoma and concomitant chronic hepatitis $\mathrm{C}$ viral infection, who achieved almost complete radiological responses to sorafenib treatment for a prolonged period. There are only 2 other reported cases in the literature reporting prolonged responses following sorafenib treatment $[4,5]$.

Chronic HCV infection is one of most common causes of HCC in Western countries. Despite the recent introduction of effective antiviral HCV therapy, the incidence of $\mathrm{HCV}$-associated $\mathrm{HCC}$ is predicted to increase over the next few years due to the epidemic of undiagnosed chronic HCV infection [1]. There is now increasing evidence to suggest that patients with $\mathrm{HCV}$-related $\mathrm{HCC}$ may attain superior survival benefit with sorafenib compared to patients who are negative for HCV. An exploratory subgroup analysis of the SHARP trial reported that patients with HCV-related HCC treated with sorafenib had a longer median overall survival compared to those with alcohol- or HBV-related HCC (14.0 vs 10.3 vs 9.7 months, respectively) [6]. In the phase III trial comparing sunitinib and sorafenib in patients with advanced HCC, median overall survival was superior in sorafenib treated patients, particularly in those with chronic $\mathrm{HCV}$ infection (17.6 vs 9.2 months) [7]. Similar results were was also reported in the phase III trial comparing brivanib and sorafenib; exploratory subgroup analyses demonstrated that the $\mathrm{HCV}$ positive subgroup of the sorafenib arm had a longer overall survival than the hepatitis $\mathrm{C}$ negative participants who received sorafenib (12.9 vs. 9.3 months) [8].

The precise mechanism underlying the possible higher efficacy of sorafenib in patients with chronic HCV infection currently remains unclear. In vitro, it has been shown that cellular expression of full length HCV enhances sensitivity to sorafenib. This was due to modulation of microRNA expression by the viral proteins, which in turn enhances apoptosis through downregulation of the anti-apoptotic protein $\mathrm{Mcl}-1$ [9].

There is also increasing evidence outlining the mechanism by which sorafenib interacts with the hepatitis $C$ virus. In vitro, sorafenib has been shown to inhibit $\mathrm{HCV}$ infection in a dose-dependent manner [10]. Multiple steps in the HCV infectious cycle appear to be affected, including inhibition of viral replication by blocking the c-Raf pathway that is normally activated by the virus, impaired secretion of $\mathrm{HCV}$ particles, and potent inhibition of viral entry and HCV cell-to-cell transmission $[10,11]$. Further studies have researched whether sorafenib may have benefit in treating chronic HCV infection - however a small study of 33 patients being treated for HCC with sorafenib failed to show any significant change in measured viral load [12]. Similarly in our 2 cases, sorafenib treatment was not associated with any reduction in the $\mathrm{HCV}$ viral load.

\section{Case presentation 1}

A 55 year old gentleman was diagnosed with hepatocellular carcinoma in September 2012, following investigations for deranged liver function tests. Magnetic resonance imaging (MRI) of the abdomen demonstrated a $4.5 \mathrm{~cm}$ liver lesion, with arterial phase hyperenhancement and venous phase washout, with an adjacent satellite nodule and invasion into a portal vein branch. The background liver appeared cirrhotic, and the spleen was enlarged. His serum alpha fetoprotein (AFP) was $1751 \mathrm{kU} / \mathrm{L}$, and a viral hepatitis screen showed chronic hepatitis $\mathrm{C}$ virus ( $\mathrm{HCV}$ ) infection and evidence of previous hepatitis B viral infection. His $\mathrm{HCV}$ viral load at baseline was $606926 \mathrm{IU} / \mathrm{mL}$. He had well compensated liver function (Child Pugh class A) and an Eastern Cooperative Oncology Group (ECOG) performance status of zero.

He was treated with transarterial chemoembolisation (TACE) as the invasion into his branch portal vein was non-occlusive, but his computed tomography (CT) scan 4 weeks post-TACE demonstrated disease progression, with an increase in size and enhancement of the primary liver lesion, progression of the branch portal vein invasion and multiple new abdominal, para-aortic and mediastinal lymphadenopathy (Fig. 1a).

He started treatment with sorafenib in January 2013, achieving a maintenance dose of $600 \mathrm{mg}$ daily after 2 months. He achieved an excellent serological response; his serum AFP level fell from a baseline value of $348 \mathrm{kU} /$ $\mathrm{L}$ to $5 \mathrm{kU} / \mathrm{L}$ within 2 months and remained suppressed thereafter. This was associated with an excellent radiological response: CT imaging after 3 months of treatment showed a significant decrease in the size of the primary liver lesion and the lymphadenopathy (Fig. 1b). Follow-up CT imaging after 6 months of treatment demonstrated disappearance of all measurable disease apart from a residual lymph node adjacent to the caudate lobe (Fig. 1c). He maintained his excellent serological and radiological response for a further 14 months, until progressive disease was seen on repeat $\mathrm{CT}$ imaging in 

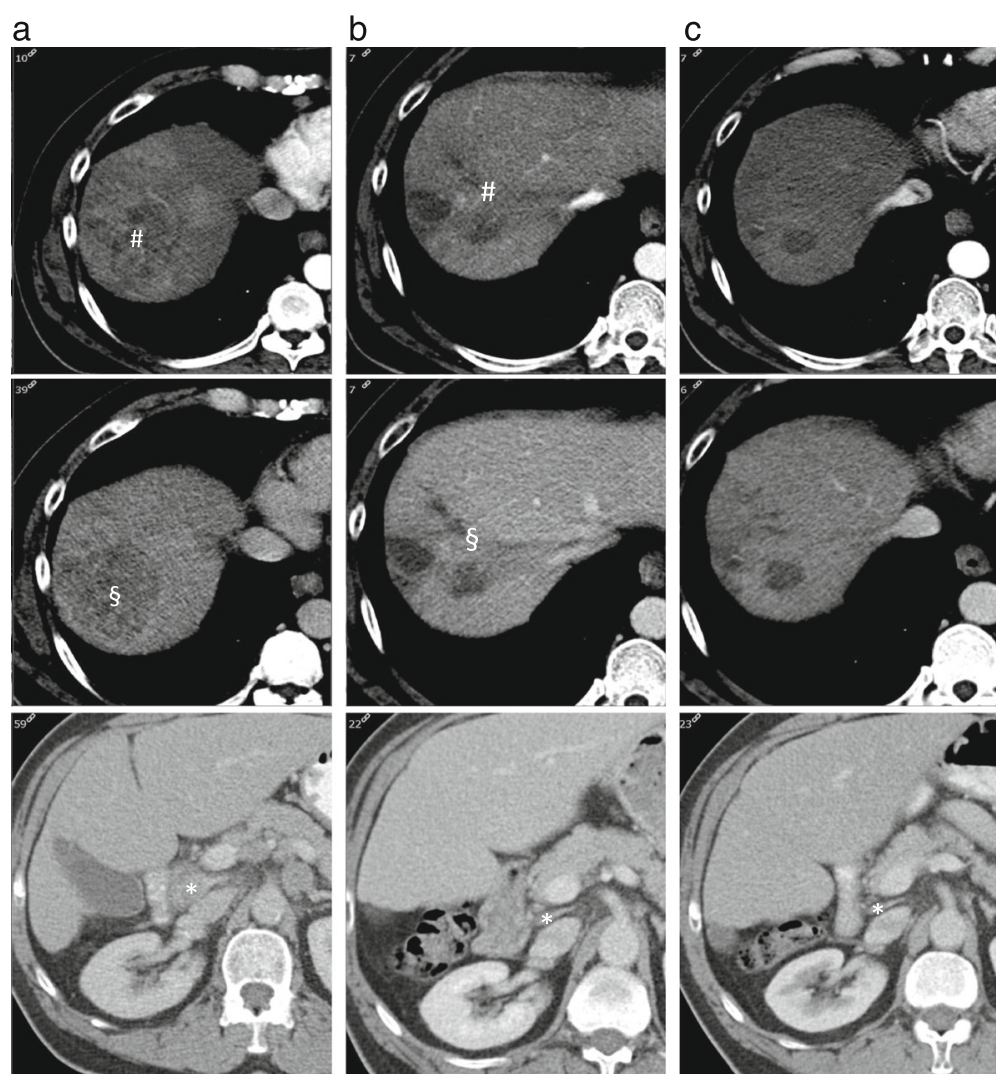

Fig. 1 Case 1 response to sorafenib. a. Triple phase CT of the liver 07/12/2012. Primary HCC with arterial phase enhancement (\# top panel) and portal venous washout (§ middle panel) with involved lymph node between portal vein and IVC (bottom panel*). b. Triple phase CT of the liver 03/04/2013. Primary HCC with reduced arterial phase enhancement (\# top panel) and portal venous washout (§ middle panel) with two cystic areas. Reduction in size of lymph node (bottom panel *). c. Triple phase CT of the liver 15/07/2013. No arterial phase enhancement (top panel) or portal phase washout (middle panel) reflecting disappearance of tumour. Residual cystic areas. Sustained reduction in size of lymph node (bottom panel *)

August 2014. He received a total of 20 months of treatment with sorafenib. Sorafenib had no effect on the patient's HCV viral load, which remained significantly elevated during this period. The patient entered a second line clinical trial and remained alive for a further 11 months following discontinuation of sorafenib.

\section{Case presentation 2}

A 75 year old lady was diagnosed with advanced hepatocellular carcinoma in June 2013 following investigations for low platelet count. A CT scan of the liver showed a $12 \mathrm{~cm}$ tumour in the left lobe with arterial phase hyperenhancement and venous phase washout, and left portal vein invasion (Fig. 2a). The background liver appeared cirrhotic. Her serum AFP level was $372 \mathrm{kU} / \mathrm{L}$. A viral hepatitis screen confirmed chronic hepatitis $\mathrm{C}$ virus infection, with a low viral load (114 IU/mL). She had well compensated liver function (Child Pugh class A) and an ECOG performance status of 1 .

She started sorafenib in July 2013, at a dose of $400 \mathrm{mg}$ twice daily. After 7 days she developed grade 2 palmarplantar erythrodysesthesia and treatment was paused and then restarted at reduced dose of $400 \mathrm{mg}$ daily. She developed grade 2 hand-foot skin toxicity again and her sorafenib dose was thus reduced further to $200 \mathrm{mg}$ daily, which was well tolerated. Repeat CT imaging after 3 months of treatment showed stable disease, however her serum AFP level had risen to $1574 \mathrm{kU} / \mathrm{L}$. Her dose of sorafenib was cautiously increased. Over the next 2 months her serum AFP level declined rapidly to $6 \mathrm{kU} / \mathrm{L}$.

Following this her liver synthetic function deteriorated and she decompensated with recurrent episodes of hepatic encephalopathy and ascites. Her treatment was paused for 4 months. Throughout this period her serum AFP level remained below 13kU/L. On review in March 2014 her liver synthetic function had improved (Child Pugh class B7), and she restarted low dose sorafenib. CT imaging in March showed ongoing stable disease despite the 4 month treatment break. Following resumption of sorafenib, serial CT scans showed reduction in the size of the liver lesion, with no tumour enhancement seen on her repeat imaging in December 2014 (Fig. 2b). She maintains her excellent serological and radiological response to date, 24 months after first starting sorafenib. 

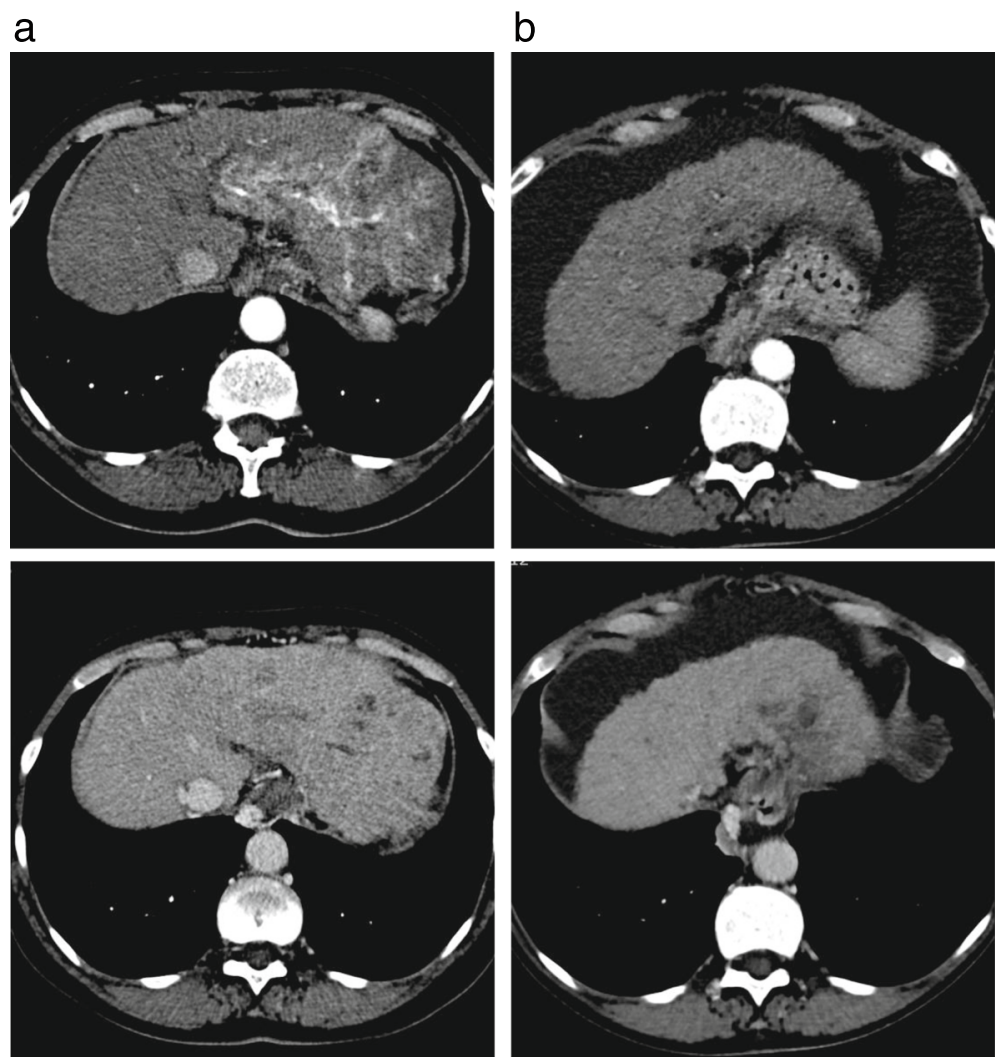

Fig. 2 Case 2 response to sorafenib. a. Triple phase CT of the liver 10/06/2013. Primary HCC with arterial phase enhancement (top panel) and portal venous washout (bottom panel). b. Triple phase CT of the liver 19/12/2014. Primary HCC with no arterial phase enhancement (top panel) or portal venous washout (bottom panel)

Her HCV viral load initially increased to $4000 \mathrm{IU} / \mathrm{mL}$ after starting sorafenib and remains elevated.

\section{Conclusions}

In patients with advanced HCC, sorafenib is the only systemic treatment that has been shown to increase overall survival $[2,3]$. Sorafenib is an orally active, multikinase inhibitor that inhibits tumour angiogenesis and cell proliferation by blocking cell surface tyrosine kinases such as vascular endothelial growth factor receptor-2/3 (VEGFR-2/ 3 ) and platelet derived growth factor receptor beta, as well as downstream signalling pathways involving the serine/ threonine kinases Raf-1 and B-Raf [13]. Its efficacy in treating $\mathrm{HCC}$ has been demonstrated in 2 randomised phase III trials $[2,3]$. The SHARP trial, undertaken in patients with advanced HCC in Western countries, showed that patients with advanced hepatocellular carcinoma treated with sorafenib had a significant improvement in overall survival (10.7 months vs. 7.9 months, $p<0.001)$ and radiological time to progression (5.5 months vs. 2.8 months, $p<0.001$ ) when compared to placebo [2]. The Asia-Pacific trial also showed that sorafenib significantly prolonged overall survival (6.5 months vs. 4.2 months, hazard ratio $0.68, p=$ 0.014) compared to placebo, in patients from the Asia-
Pacific region [3]. In both trials a partial response was observed in only a small minority of patients ( 2 and 3\% respectively) and no complete responses were seen.

A small number of cases of complete response to sorafenib treatment have now been reported worldwide $[4,5$, 14-17], however a prolonged response ( $>18$ months) has only been reported in 2 cases, both of whom had HCVrelated HCC $[4,5]$. Both of our cases also had HCVrelated $\mathrm{HCC}$ and demonstrated prolonged responses $(20$ and 24 months, respectively) to sorafenib treatment. The 2 cases presented here add to the accumulating evidence that patients with HCV-related HCC may attain superior survival benefit with sorafenib compared to patients who are negative for HCV. The second case is particularly noteworthy, because the prolonged response was achieved even with dose reductions and a treatment break (due to decompensation), and highlights that even with dose reductions, significant response to sorafenib can be achieved.

\section{Abbreviations}

AFP: Alpha fetoprotein; CT: Computed tomography; ECOG: Eastern cooperative oncology group; HBV: Hepatitis B virus infection;

HCC: Hepatocellular carcinoma; HCV: Hepatitis C virus infection; MRI: Magnetic resonance imaging: RNA: Ribonucleic acid; TACE: Transarterial chemoembolization; VEGFR: Vascular endothelial growth factor receptor 


\section{Acknowledgements}

Not applicable.

\section{Funding}

No funding was received.

\section{Availability of data and materials}

All the data is contained in the manuscript.

\section{Authors' contributions}

CA and PE drafted the manuscript. AP provided the radiological images for this manuscript, and was a major contributor in drafting the manuscript. SS, PP and YTM revised the manuscript critically for important intellectual content. All authors read and approved the final manuscript.

\section{Competing interests}

The authors declare that they have no competing interests.

\section{Consent for publication}

Written informed consent was obtained from both patients for publication of this case report.

\section{Ethics approval and consent to participate}

Not applicable.

\section{Author details}

${ }^{1}$ The Cancer Centre, University Hospitals Birmingham NHS Foundation Trust, Edgbaston, Birmingham B15 2TH, UK. ²Department of Radiology, University Hospitals Birmingham NHS Foundation Trust, Edgbaston, Birmingham B15 2TH, UK. ${ }^{3}$ The Liver Unit, University Hospitals Birmingham NHS Foundation Trust, Edgbaston, Birmingham B15 2TH, UK.

Received: 1 July 2016 Accepted: 8 February 2017

Published online: 14 February 2017

\section{References}

1. de Oliveria Andrade $L$, D'Oliveira A, Melo RC, De Souza EC, Costa Silva CA, Paraná R. Association between hepatitis $C$ and hepatocellular carcinoma. J Glob Infect Dis. 2009;1:33-7.

2. Llovet JM, Ricci S, Mazzaferro V, Hilgard P, Gane E, Blanc JF, et al. Sorafenib in advanced hepatocellular carcinoma. N Engl J Med. 2008;359:378-90

3. Cheng AL, Kang YK, Chen Z, Tsao CJ, Qin S, Kim JS, et al. Efficacy and safety of sorafenib in patients in the Asia-Pacific region with advanced hepatocellular carcinoma: a phase III randomised, double-blind, placebocontrolled trial. Lancet Oncol. 2009;10:25-34.

4. Sacco R, Bargellini I, Gianluigi G, Bertini M, Bozzi E, Altomare E, et al. Complete response for advanced liver cancer during sorafenib therapy: case report. BMC Gastroenterol. 2011;11:4.

5. Gerardi AM, Stoppino LP, Liso A, Macarini L, Landriscina M. Rapid longlasting biochemical and radiological response to sorafenib in a case of advanced hepatocellular carcinoma. Oncol Lett. 2013;5(3):975-7.

6. Bruix J, Raoul JL, Sherman M, Mazzaferro V, Bolondi L, Craxi A, et al. Efficacy and safety of sorafenib in patients with advanced hepatocellular carcinoma: Subanalyses of a phase III trial. J Hepatol. 2012;57:821-9.

7. Cheng AL, Kang YK, Lin DY, Park JW, Kudo M, Qin S, et al. Sunitinib versus sorafenib in advanced hepatocellular cancer: results of a randomized phase III trial. J Clin Oncol. 2013;31(32):4067-75.

8. Johnson PJ, Qin S, Park JW, Poon RT, Raoul JL, Philip PA, et al. Brivanib versus sorafenib as first-line therapy in patients with unresectable, advanced hepatocellular carcinoma: results from the randomized phase III BRISK-FL study. J Clin Oncol. 2013;31(28):3517-24.

9. Braconi C, Valeri N, Gasperini P, Huang N, Taccioli C, Nuovo G, et al. Hepatitis C virus proteins modulate microRNA expression and chemosensitivity in malignant hepatocytes. Clin Cancer Res. 2010;16(3):957-66.

10. Descamps V, Helle F, Louandre C, Martin E, Brochot E, Izquierdo L, et al. The kinase-inhibitor sorafenib inhibits multiple steps of the Hepatitis C Virus infectious cycle in vitro. Antiviral Res. 2015;118:93-102.

11. Himmelsbach K, Sauter D, Baumert TF, Ludwig L, Blum HE, Hildt E. New aspects of an anti-tumour drug: sorafenib efficiently inhibits HCV replication. Gut. 2009;58:1644-53.
12. Cabrera R, Limaye AR, Horne P, Mills R, Soldevila-Pico C, Clark V, et al. The antiviral effect of sorafenib in hepatitis c-related hepatocellular carcinoma. Aliment Pharmacol Ther. 2013;37(1):91-7.

13. Wilhelm SM, Carter C, Tang L, Wilkie D, McNabola A, Rong H, et al. BAY 439006 exhibits broad spectrum oral antitumour activity and targets the raf/ MEK/ERK pathway and receptor tyrosine kinases involved in tumor proliferation and angiogenesis. Cancer Res. 2004;64:7099-109.

14. Nakazawa T, Hidaka H, Shibuya A, Koizumi W. Rapid regression of advanced hepatocellular carcinoma associated with elevation of des-gamma-carboxy prothrombin after short-term treatment with sorafenib - a report of two cases. Case Rep Oncol. 2010;3:298-303.

15. Di Lorenzo G, Imbimbo M, Leopardo D, Marciano R, Federico P, Buonerba C, et al. A long-lasting response to sorafenib treatment in an advanced hepatocellular carcinoma patient. Int J Immunopathol Pharmacol. 2010:23(3):951-4.

16. Chelis L, Ntinos N, Souftas V, Deftereos S, Xenidis N, Chamalidou E, et al. Complete response after sorafenib therapy for hepatocellular carcinoma in an HIV-HBV co infected patient: Possible synergy with HAART ? A case report. Med Oncol. 2011;28 Suppl 1:S165-8.

17. Inuzuka T, Nishikawa H, Sekikawa A, Takeda H, Henmi S, Sakamoto A, et al Complete response of advanced hepatocellular carcinoma with multiple lung metastases treated with sorafenib: a case report. Oncology. 2011;81 Suppl 1:152-7.

\section{Submit your next manuscript to BioMed Central and we will help you at every step:}

- We accept pre-submission inquiries

- Our selector tool helps you to find the most relevant journal

- We provide round the clock customer support

- Convenient online submission

- Thorough peer review

- Inclusion in PubMed and all major indexing services

- Maximum visibility for your research

Submit your manuscript at www.biomedcentral.com/submit
) BioMed Central 